\title{
Management Environment and its Impact on the Efficiency of Purchasing and Operating the Technology
}

\author{
Jabber Al Nabulsi ${ }^{1}$ Hatem S. A. Hamatta ${ }^{2 *}$ Rasha A. Al-Kayyal ${ }^{3}$ \\ 1. Department of Maritime Sciences, Aqaba University College, Al Balqa Applied University, P. \\ O. Box 1199, (77110), Aqaba, Jordan \\ 2. Department of Applied Sciences, Aqaba University College, Al Balqa Applied University, P. \\ O. Box 1199, (77110), Aqaba, Jordan \\ 3. Department of Finance, Aqaba Special Zone Authority, P. O. Box 2565, (77110), Aqaba, \\ Jordan \\ *E-mail of the corresponding author: Hatem@bau.edu.jo
}

\begin{abstract}
Technology topic gained very large importance in the second half of the previous century; in the majority of countries, and this importance is increasing dramatically due to the hopes that nations put on this technology and the promising benefits from using it in the advancement and development of different areas. This isn't only interest the developed countries, but also it was extended to include the non-developed countries, which is trying hard to get rid of the backwardness that suffers and seeks to achieve the development, advancement, and progress through the use of technology, after several aid programs failed to achieve what was expected from them. It showed clearly that gap is expanding between the developed countries and the non-developed, which prompted the latter to work hard in order to get rid of the dependency that developed countries impose on it, by attempting to focus on the technology purchase process, its advance operation, and use it in the different development programs, benefit from it, and disseminate it. But as far as Jordan concern, which considers one of the non-developed countries, the leadership in it gave a special importance to the science and technology over the last 50 years, when the first Jordanian University was established in Amman at the start of the second half of the last century, and now their numbers exceed thirty-one universities that work on graduating scientific professions. This makes Jordan differ from the other non-developed countries, add to that Jordan became one of the countries that export high-level scientific professions to the Gulf, USA, and European countries. However, at the present time, this society doesn't provide adequate technological support for the development process, and this study aims to address the following topics:
\end{abstract}

First: study methodological framework.

Second: the concept and importance of technology.

Third: the general goal for purchasing and operating technology.

Fourth: the strategies for purchasing and operating technology in Jordan.

Fifth: the various environmental factors that influence the decision of purchasing and operating technology.

Sixth: the contributors to decision rationalization of purchasing and operating technology.

Seventh: the field study.

Keyword: Management environment, purchasing, operating, technology, reflection, decisions, strategies, goals, concepts, methodological framework, contributors.

DOI: $10.7176 / \mathrm{IKM} / 9-6-07$

Publication date:July $31^{\text {st }} 2019$

\section{Study methodological framework}

It is impossible for the development and advancement to be achieved without the combination of several factors, the most important of those is finding a high level efficient management capable of making the correct decisions of purchasing and operating technology; where (purchasing occupies a special and important position in most organizations, because the purchased spare parts, components, and supplies represents between $(40 \%$ $60 \%$ ) from the sales value of finished products of those organizations) 2 , and this what any organization strive for, which is trying to achieve the highest level of efficiency in purchasing and supplying management of the technological operation element, therefore the most important components of management process is making the special decisions of strategic planning for the process of purchasing and operating the technology. 
While the purchasing process in Jordan; especially in regard to purchasing the equipment and technological tools and obtaining it from the foreign markets, due to the fact that Jordan own an old industrial projects represented in the phosphate extraction project in the 50's of the last century and export it, which requires tools for drilling and milling, handling tools inside the location, and export port, and what requires also for extracting dead sea salts, such as potash and other minerals, and what related also to the cement and mines extraction, the extraction of petroleum from oil shale, the software industry, solar energy equipment, modern communication systems, and pharmaceutical industry. All of this casts a big burden on the management shoulder to make rational decisions in the processes of purchasing and operating technology.

\subsection{Study problem:}

The problem of the study restricted to the constraints and barriers that imposes by the internal and external management environment on the decision maker for purchasing and operating the technology in non-developed countries, in general and Jordan in particular.

\subsection{Study objectives:}

The study aims, with the role it seeks for the impact of management environment and its reflection on the efficiency of purchasing and operating technology to the following goals:

- Clarify the concept and importance of technology for the non-developed countries, in general and Jordan in particular.

- Clarify the impact of internal and external management environment on the efficiency of decision maker at purchasing and operating technology in the non-developed countries, in general and Jordan in particular.

- Identify the obstacles that obstruct the process of purchasing and operating technology in the nondeveloped countries, including Jordan.

- Identify level of readiness at the research and advisory centers in Jordan to provide the advisory service in the field of purchasing and operating technology.

1.3. Study questions:

1. What are the difficulties and obstacles that obstruct and face the decision of purchasing and operating technology in the non-developed countries, including Jordan?

2. What are the restrictions and limitations of internal and external management environment?

3. What is the impact of owning a technology on the development of Jordan society?

4. What is the role of research and advisory centers in Jordan as a contribution to rationalize the decision of purchasing and operating the technology?

1.4. Study hypotheses:

H1 The decision of purchasing and operating the technology faces obstacles and barriers from the internal and external management environment.

H2 The decisions of purchasing and operating the technology in Jordan falls under the centralized decision making without returning to professional and technical levels.

H3 The private sector owns flexibility in making the decision of purchasing and operating the technology, as oppose to the public sector.

H4 The scientific and technological research centers in Jordan still limited in its potentials to provide the special service of purchasing and operating the technology.

\subsection{Study approaches:}

There are multiple approaches for studying the process of purchasing and operating the technology and modern systems, some of those studies depend on the economical approach which focuses on the physical aspects about the impact of technology transfer on the process of maximizing profit without giving any attention to the embodied technology, such as management communications systems, information systems, and service systems. Others also focused on the social approach of technology, in terms of the impact of technology transfer on the interaction of various society potentials and features and what technology leads to, such as transferring the industrial cultures and traditions between nations. The research was headed to the management approach to examine the research topic, which requires it the direction of this study:

\subsection{Study methodology:}

The study depends on both of and descriptive methods to indicate the results: 
a) Descriptive research:

The researcher aims through this type of research to arrive at an accurate and comprehensive description for all variables that affect the process of purchasing and operating the technology, considering that technology is the right way to achieve total development.

b) Analytical research:

The researcher aims through this type of research to use the appropriate statistical methods for the type of data which have been collected through the survey lists that meets the purposes of analysis to reach the appropriate recommendations related to clarify the relationship between the project management work environment and their reflections and impacts on the process of purchasing and operating the technology.

\section{The concept of technology and its importance:}

\subsection{The concept of technology:}

The word technology is a Greek word originally, consists of two syllables; first section: techno and means craft, skill, or art, and the second section: Logia, meaning knowledge, science, or study, and accordingly, the word "technology" means performance or implementation science. A lot of scientists have reported several other definitions for the word technology, which tend to converge together more than it's diverge (Anissimov, M., \& Bronwyn H. (2018)).

The common definition for the term technology is using computer and modern devices, which certain people consider it a narrow perception because computer considers a result of this technology, while the technology intended by this term means way of thinking and problem solving, and it's a thinking method that individual arrive with it to the desired results, which is a mean and not a result, and it's also a thinking method to use information, knowledge, and skills in order to reach a results that satisfy the human needs and increase their capabilities, and therefore technology means the optimal use of scientific knowledge and its applications, and recruiting it and adapting it to serve humans and their welfares (Anissimov, M., \& Bronwyn H. (2018)m Ballou, R. H. (2004)). The word technical in the Arabic language used as a synonym for the word technology in its modern definition, which includes a set of scientific secrets, industrial experiences, registered and nonregistered inventions, machines, equipment, and all assets of technical knowledge in the various types and forms.

\subsection{Definition of technology:}

As there is disagreement about the concept of technology, there are also many definitions where each one of them serves a specialized field; for example the communications workers identify technology as a means of communication between human beings to transmit and publish data or information through the various communication devices, it also was defined by the industrialists in the fields of information and management systems, and technology considers also a source of knowledge which is dedicated to manufacturing tools, processing activities, and extracting materials, which can be described as technology of products, processors, and organizational structures, where it's used by humans in order to increase their abilities, possibilities, and potentials, therefore humans consider the most important factor in any technological system (Ballou, R. H. (2004)). In addition, the technology also considers as an applied science to solve the problems that mankind faces, and it should be noted that science and technology are entirely two different things, but they works side by side to achieve a certain goal or solve a problem (Ballou, R. H. (2004)).

It illustrated from the previous definitions the difference range of views related to the definition of technology, some sees it as a development in machines and equipment, others adds to it the technical knowledge and production methods, and some also goes beyond the physical concept of what the word technology means to a general and comprehensive definition, where its seen as not only the embodied things but also the non-embodied, such as management and financial systems, and production methods and techniques that linked it with science and its various applications.

\subsection{The importance of technology:}

It is clear after the previous display of technology concept, that indication level of technical and scientific advancement exists in all fields, which at the end, leads to know the related importance of technology regarding the developed countries in general, and the non-developed countries in particular.

However, the concern about this topic of technological development and its relationship to the economic development considers new for the developed countries ; it is rare to find an interest in any book about the economic development before the year 1964, and in this year the President of the United States requested the formation of a committee to search for the necessary means and methods to promote economic growth by using the technological development and advancement.( Ismail, M. (1976)) In addition, the developed countries interest in this topic of technological development is due to a combination of factors, including:- 
- The increasing beliefs that economic growth rate depend heavily on the technological development rate.

- The growing interest in weapons development, especially in the areas of advanced warplanes and missiles, and atomic and hydrogen bombs, which motivate the governments to give considerable support to the special researches about these areas.

- The emergence of fierce competition between the industrial projects within the one country itself and between countries regarding the production of goods, where the capability here will be to the one who produce new goods and invent modern production techniques.

- The fears that occurs from the technological advancement by increasing unemployment rates, as a result of the automated system, which great the need to find jobs for those who lost them.

If the developed countries had this much interest in technology, then the non-developed countries interest is increasing and doubling, which felt the expansion of the gap between them and the developed countries, and that gap will increase if those countries don't accelerate in the making of economic and social development process, which mainly focuses on the utilization of advancement that science and technology are achieving in all areas, because the backwardness and retardation that non-developed countries suffer, returns mainly to a reduction in the scientific and technological research level, whereas its high in the industrial countries, and that technology is only a benefit of the continuous and cumulative scientific efforts. In this respect, the non-developed countries have to benefit from the expertise and experience of industrialized countries, in order to begin the manufacturing process through importing, purchasing, operating, and using the technology wisely to achieve greater physical and social returns, and increase the contribution levels of development goals achievement.

Perhaps the peak interest in the technology topic can be represents the United Nations concern of it, where a framework has been developed for the creation of a new world economic system, and this interest represented in the assistance programs that carried out by the organizations, and in this regard the General Assembly of the United Nations passed in 1970, 1975, and in 1979 several recommendations regarding the transfer of technology to the non-developed countries, some of those are:

1. The need to increase the capacity of non-developed countries to incorporate more in science and technology and create the necessary conditions for that.

2. The need to develop technology that align; in its essence with available conditions in the non-developed countries.

3. The need to develop non-developed countries expenses in the areas of technological researches and development.

4. The need to set up a special program to promote and transfer science and technology, and overcomes the obstacles that interrupt this path, and support the non-developed countries in their efforts to develop their capacity to absorb more in science and technology.

5. Work to reorganize the international relations, with regard to science and technology.

Despite all that, it shows the level of significant technology and the role participates in it, which makes economic growth enjoyed by the modern world.

\section{The general objectives of purchasing and operating technology:}

This item includes a review for the economic and social objectives of purchasing and operating the technology: 3.1. The economic goal:

Non-developed countries, including Jordan seeks to purchase and operate technology for the desire of developing industrial capabilities at higher production rates, which consider very low when measured against the high production rates or productivity in the developed countries, due to the technological development in these countries.

"It found that $(90 \%)$ of the increase rate per capita in USA; in the long period due to special factors in the technological development and higher level of education"( Mansfield, E (1968)), but the other side about purchasing and operating technology in the non-developed countries lies in the development and advancement of local technology, in addition to covering and insuring the domestic market needs of goods that are not available locally, which with it can do without importing these products or exporting the surplus of it.

It is known that non-developed countries are not able to perform the invention process, which requires considerable costs and long time period. Therefore, the non-developed countries have found that the only way to take advantage of the technological advancement will be at purchasing technology from the developed countries, with the work to develop it and adapt it to align with the circumstances and needs of the country. The economic objectives for purchasing technology in Jordan doesn't go beyond the economical goals that non-developed countries seek to achieve, but it is possible to view the economic objectives of purchasing and operating technology in Jordan, by the following points:

- Increase the productivity of the Jordanian worker. 
- Reduce production costs to face the strong competition on foreign goods locally.

- Increase the quality level of Jordanian products to go without importing it from abroad, and therefore the possibility of exporting the surplus to the Arabic countries in general and the Gulf countries in specific, which ensures the achievement of a surplus in the trading balance of Jordan.

- There are many traditional sectors need to use advanced technology, due to high wages of employees in it, as a result of labor migration from these sectors to the others.

- The use of advanced technology in Jordan plants helps to utilize raw materials and export it as a finished product to achieve better tangible returns, such as mining, pharmaceuticals, telecommunications, software, and shale oil utilization.

- Purchasing technology usually would be accompanied by changing the attitudes of prevailing management behavior to ones that agree with the technology operation needs, which gives a significant return to the development process.

- Purchasing and operating technology usually would be followed or accompanied by purchasing and operating sophisticated working methods, systems, and procedures in all fields.

\subsection{The social goal:}

Initially, the economic objective of purchasing and operating technology is a pure social goal, increase in worker productivity lead to increase the productivity in general, and also entails an increase in worker income, which is a required social goal to elevate individual and society standard of living, and the same for increasing quality level and reducing production costs, which works toward satisfying the required and desired goods and services of society. Increase the country sources of foreign financial resources, by exporting the goods and services surpluses, and utilizing the inoperative capabilities and resources will also lead to support the political and economical positions of the country. Using the sophisticated methods and accompanied managerial, economical, and financial systems to purchase the technology will also work; in the long term to establish new industrial concepts and values handed down from one generation to the next.

Despite the social and economical objectives achieved from purchasing and operating technology on the national level, it remains an important factor and a main goal for purchasing and operating the sophisticated technology, which is working to keep up with the scientific and technological international development, bringing down the gap between the industrialized countries and the non-developed countries, and then working to get rid of the economic reliance on industrialized nations and conditions and restraints they impose on selling and using the technology. The impact of purchasing and operating technology also became large on changing a lot of concepts and beliefs that don't align with the manufacturing phase, which eventually imposes radical changes in the prevailing education systems and converted them into vocational and technical educations, which serves the manufacturing phase rather than focusing on public education. The manufacturing and purchasing of technology also requires advances in the education level of the country, which still relies on the academic education that forms more than $(90 \%)$ of the public education, where this percentage causes a delay in the process of absorbing foreign technology and benefiting from it in a better way.

\section{The strategies for purchasing and operating technology in Jordan:}

The research discussed in section, the different strategies for purchasing technology by the Jordanian companies with showing both positive and negative aspects of each, and then identifies the most appropriate strategies for capabilities and requirements of the Jordanian environment. It shows through this section the significant level of making the decisions concerning the adoption of specific strategy for purchasing and operating the technology and reflection of those decisions on the economical, social, and political aspects. Therefore, its importance to create a specific strategy for the Jordanian buyer, in order to be able to avoid the negative consequences that may result from taking advantage of companies exporting the technology, and also the adaptation of government-backed specific strategy will achieve returns for companies and society, characterize in reducing the purchasing cost and obtaining high quality technology and compatible with the Jordanian environment.

As a result, taking a decision related to adopting a specific strategy to purchase and operate the technology requires high managerial efficiency that takes into its account the cost of factors associated with this decision.

We can imagine the significant level of decision about purchasing the technology, in case if the Jordanian companies spent a value of (15) billion dollars on purchasing and operating the technology; during the five-year plan, and if these companies were able to save $(5 \%)$, as a result of following certain purchase strategy, the saving would be (750) million dollars, which is higher than the yearly income of many Jordan sectors.

Since Jordan is working now to achieve comprehensive development plan, and since this development requires huge capital investment, and therefore this plan will depend largely on the purchasing and operating processes of technology, and this requires very large concentration on examining the correct ways which possible through it to obtain the appropriate technology, and that's what we mean by "Technology purchasing strategy". 


\subsection{Elements and features that must be taken into consideration when preparing the technology purchasing strategy.}

The need to establish clear and specific purchasing strategy moves us to identify the factors that must to be taken into account, when setting up the strategy of purchasing and operating the technology, which includes the following:

1. The integration between purchasing strategy elements and the company overall strategy:

This means all parts that formulate the company's strategy have to participate in achieving the general goal of the company consistently and well balanced.

2. The integration between the strategy elements and the company's internal and external environment:

This means it isn't necessary if the strategy is appropriate for a particular environment, it could be the same for another environment, meaning that purchasing a technology that is suitable for the conditions of industrialized developed countries may not be suitable for the non-developed countries, but each non-developed country represents an existing case in itself, regarding the impact of environmental factors on purchasing the technology strategies, which represented in the government intervention, market size, globalization, national income size, level of main environment, and population density.

3. The alignment between purchasing strategy and available resources:

The management and operation of technology needs financial resources, and previous experience in these areas, and employees have to have readiness to acquire it, and it also need to provide and create other preparations and equipments, such as buildings and roads.

4. The Assessment of risks associated with purchasing and operating the technology:

While the purchase of various types of technology involves risk at higher degree compare with the routine purchasing decisions, this needs some calculations for the risk level associated with this operation, whether it was financial or managerial.

5. The possibility of accessing technology at the right time:

The technology gets purchased in order to achieve specific goals, such as exploiting some of the marketing opportunities, or overcoming some of the productivity constraints, and others. There is no doubt the time factor here considers an important element in achieving those goals.

\subsection{The different strategies for purchasing technology:}

While the decision of purchasing and operating technology influence by many factors, whether it was represented by the company's internal conditions, surrounding external environment, or suppliers environment, it requires the replacement of special strategy that agrees with these factors, and take into account the examination of each individual strategy very carefully, since each strategy have number of advantages, and also disadvantages. In addition, each strategy might be appropriate in certain circumstance or specific environment and become inappropriate in other circumstances or environments.

1. Direct purchasing and turnkey agreements:

This method usually done by either connecting with the producer, contacting the dealer, or calling on one of the think-tank expertise which specialized in the commercial mediation process, in this way the producer or supplier of technology performs all the processes associated with delivering the technology to the buyer, where the producer or supplier will put the designs, layouts, drawing, and buildings; if it was necessary, and also may train the technical staffs on how to operate and deal with the new systems.

2. Obtain patent for technology utilizations:

This method considers the simplest way to obtain the technology, for both buyer and seller, and according to this method the company that owns the technology gives the buyer who obtain the patent the rights to use the technology; under negotiation, and this may be assimilated in the innovative production methods, trademark (major brand) utilization, or trade secrets, where the buyer pays an annual amount or a certain percentage from the utilization revenues, and this method has been implemented by the soft drink companies.

3. Joint investment:

The use of this investment type became popular, as one of the important methods to transfer technology, and this type assimilated in establishing a joint project between two sides; the foreign and the national, where the latter owns (51\%) from the capital or above, and usually the foreign party provides the technology or the modern systems as part of the capital share, in addition to performing other works.

4. Purchasing part of the project:

This method assimilated in purchasing part of the technology-based project, where the buyer may only purchase a specific production line, purchase a particular engine without buying the whole machine, or purchase the raw material preparation method without getting the used machineries (Abu-Ismail, F (1983)).

Each of these methods has their advantages and disadvantages, and the ideal method is the one that aligns with the circumstances and needs of the buyer, and achieves an added value or new addition to the society.

\subsection{Problems of purchasing and operating the technology, and ways to avoid it or overcome it:}


There are many problems associated with purchasing and operating the technology, which Jordan should avoid by following these steps:

1. Create specialty device associated with the technology issues:

It's a specialty device affiliated with the Royal scientific association that deals with many issues related to the assessment of resources, selection of technology, systems, and modern procedures, differentiate between them, and select the best that meet the needs of the country. It also examine the best terms and conditions for obtaining them, and making sure it's an advisory device, in relation to preferences and sources of technology, in addition to its authority of not allowing the import of technology opposite to the country policy, conditions, and laws, which are incompatible with the Jordanian environment.

2. The difficulty of purchasing and operating technology:

This requires a special system for purchasing and operating the technology, which takes into account the financial ability to provide those currencies.

3. Direct foreign investment:

It's one of the methods for obtaining technology, and this subsequently imposes on Jordan to create the appropriate climate for the investment process, in order to encourage technology owners, individuals, and countries to bring it into Jordan.

4. Prepare special tax legislation:

These tax laws encourages investors who bring in specific types of technology that align with the country needs and requirements.

5. Population density considerations and its social conditions.

\section{The various environmental factors that impact the decision of purchasing and operating technology:}

The research displays in this part the relationship between technology, management, and environment dealing with the concepts of management and environment related to the project; both internal and external, in addition to the special environment of the technology suppliers.

\subsection{Management and environment:}

It was agreed previously, that the elements of management processes, don't go out the planning, organizing, directing, and controlling, which are bare elements of time and space influence, and in this sense, the teaching process of the fundamentals and principles of management science proceeded as an absolute and universal implementation of principles, and foundations, and therefore Europe advanced in the industrial revolution, followed by America, then came Japan; the small country in its population, lack of resources, and size, it transferred and took the technology and knowledge from America and Europe, competed with them, and surpass them in certain industries.

The industrial rank that Japan arrived to needs an explanation, and the answer on it, can be through linking the role played by the environment in the management process, and therefore on the relationship of each one of them with the technological advancement in Japan. What happened in Japan made the management scientists recently refers to the existence of environment role in the success of establishment, through their study of what named systems analysis. Consequently, any institution don't live in isolation, it's a small part of one system where companies' elements of single production compete, and this system in return is part of a larger system called circumference of the institution or external environment, and from here the concerns about the environment element began in the management process. In addition to the elements mentioned earlier, and under the new concept of governance, the institutions started to work on satisfying the desires, requirements, and demands of the environment in which it operates.

\subsection{Environmental factors of the project and its impact on the decision of purchasing and operating} technology:

The various environmental factors played a great role on the decision to purchase and operate the technology, because this decision was taken by the industrial enterprises, therefore, what applies to the behavior of the final consumer doesn't necessarily applies to the behavior of industrial buyer, or responsible person for making decisions about purchasing and operating the technology. Researchers see a need to expose the environmental factors that affect the decision of purchasing and operating technology, according to the following division:

Internal environment factors of the project:

The meaning of organizing is humans gathering aims to achieve a common goal, which means that institution organizational environment and its ability to purchase and operate the technology considers one of the important factor that required examination to identify the internal environment of the project, and does the environment favors and encourages purchasing and operating the technology, or stands in the way of achieving it. Furthermore, the decision to purchase and operate the technology usually results in an increase in the importance of certain department, on the account of others, or may lead to employees laid off as a result of operating the 
technology. As a result, the importance of organic organization takes the form of a team work, that doesn't put restrictions on purchasing and operating the technology, unlike the situation for traditional organization, which depends on the managerial relationships at the top and concentration of power in the hands of a single or few individuals, and likewise for the rest of the internal factors, such as financial resources and competition.

According to that, the efficiency of certain department from the other departments, assimilates in the ability of decision makers in the company to analysis and control the internal phenomena in the company, such as production, finance, purchasing, and others. This recognition depends on the clear vision of organization objectives, decision makers degree of openness to the international market, and the advanced production and management systems, within each market, which makes them more capable to recognize the appropriate for their company's' environment, and makes them more responsive to it.

Company's organization structure:

The company's organizational structure plays an important role in the decisions making process of purchasing and operating the technology, the existence of an organizational structure with clear policies and simplified procedures, especially in the purchasing field, in addition to enjoying visible, interactive, and responsive management systems with the changes, which in no doubt helps to produce a group of talented managers to make the decisions related to purchasing and operating the technology.

Organizational behavior within the company:

The process of purchasing and operating technology isn't a routine, but it have clear and visible impacts on the marketable, productive, and financial aspects, therefore decisions like these one couldn't be concentrated in the purchasing department, but it needs the assistance and cooperation of all departments in this field, because the decision of industrial purchases considers one of the significant factor in the product final cost, competitiveness and profitability. This requires from the prudent and mindful management to be aware of all surrounding circumstances of the project internal environment, including preparation of the human being that will operate the machines and implement the purchased systems, and also the efficient management is the one works to create synergy, coherence, and strong relationships between all departments within the project, in order to achieve the desirable goals of purchasing and operating the technology.

External environmental factors of the project :

There are numerous studies that have been conducted to find out the impact of external environmental factors on the management process, and the level of impact of these factors on the decision makers of purchasing and operating the technology.

There are two studies that have been done in this field, the first was done by Richman \& Farmer (Farmer, R. N., \& Barry M. R. (1966)), and the second was done by Ezzedine, S. (Ezzedine, S. (1981)), where in both identified the impact of environmental factors on the management process, and highlighted the importance of these factors in determining the efficiency of management process. The study also underlined, in addition to the previous management factors, the new environmental restrictions and constraints that impact the efficiency of management process and these are:

1. Educational restrictions:

The educational restrictions and limitations assimilates in society illiteracy level, availability level of the specialized technical and vocational training, and efficiency level of the higher education and management development programs, which corresponds with the required needs. These factors reflects and determines the type and quality of prevailing management, and its efficiency in the decisions making related to purchasing and operating the technology.

2. Cultural and social restrictions:

This restriction assimilates in the nature of general direction in the society, their views towards the managers, and the nature of the dominant methods and tools, in terms of power and relationships between the boss and his subordinate. It also assimilates in the level of current cooperation between the different groups within society, such as unions, corporations, associations, and confederations, and the management, in addition to the society view towards wealth and returns, its view about implementing the scientific method, and the willingness of society members toward change, and its level of acceptance to the subject of purchasing and operating technology, and the procedures accompanying it.

3. Political and legal restrictions:

These restrictions include several important variables, including:

- Rules and principles associated with the management process.

- National security and defense policy.

- Foreign policy.

- Political stability.

- Political body.

- Flexible law and regulations, and legal changes. 
For example, it's found that decisions made under stable political conditions differs from those made under restricted political circumstances, and there are also laws to protect the domestic products and other laws to deal with money, funds, or currency, therefore an environment like this one, control the decision makers of purchasing and operating technology.

4. Economical restrictions:

The economical factors clearly affect the efficiency of management and decisions made, these restrictions assimilates in the prevailing property system in the society, the competition concept, and the extent of government interference in the protection of economic systems, and control the activity of institutions and markets. There are also other factors that have direct impact on the decision associated with purchasing and operating the technology, including:

- Increase or decrease the market size.

- Increase or decrease the tariffs on imported technology.

- Availability level of technological dimension in the imported products and machines.

- These combined factors affect the management in making decisions of purchasing and operating the technology.

- Suppliers and distributors environment and its impact on the decisions of purchasing and operating technology

One of the important factor in purchasing and operating technology assimilates in the factors associated with the supplier environment, where any decision taking by the governments of companies producing the technology will directly impact the purchasing party, perhaps the greatest example on that, the US government's decision to prevent the export of advanced technology to the Soviet Union, in the wake of its invasion to Afghanistan, as well as the recent sanctions of the US and European exports on Iran after the disagreement over the development of its nuclear reactors, and also the industrial companies recent banned on selling any technological products to North Korea, and what happened with Cuba before that. "The companies producing the technology are the one working to restrict the exporting types of foreign markets and impose restrictions associated with exporting it, such as limits the freedom of purchasing other types of complementary technology to the negotiated technology, or prohibiting the export of finished product to certain global markets, and other limitations that requires special skill from the negotiating team" ( Fawzi, A.-A. (1983)), These companies may also imposes certain conditions for payment, or it want to deliver all or part of the project or waiver of the patent, and also find certain companies monopolize certain types of the technology, and as a result finds that technology supplier environment in America and European countries are subject to laws and restrictions different from those limitations and restrictions impose on institutions within the Soviet Union, in dealings with buyers.

After a brief review of the environmental factors surrounding project, and its impact on making the decision of purchasing and operating technology, it demonstrated the extent of management importance and efficiency in impacting the coherence between these variables and optimize its utilization, and also the management's ability to develop and adapt these factors for the decision of purchasing and operating technology, therefore govern the management efficiency in this process that benefit the firm and society as a whole.

\subsection{Management awareness of the technology:}

The process of purchasing and operating the technology faces several problems, on both levels of the developed countries, and the non-developed countries, and all of these limit the best use of technology.

\section{The contributors to decision rationalization of purchasing and operating technology:}

Today institutions no longer live in isolation from the external environment, but become impacted by the areas surrounding it; and in the same time have impact on those areas, as it considers one of the open systems. The project management also is no longer able to make all the decisions related to its various subjects; as it did in the past, due to the complexity and multiplicity of things, issues, and interests, multiple areas of specialization, diversity and increase production in the middle of the sharp competition, government intervention, and laws regulating the import process, and the currencies exchange. These issues and affairs, makes it a necessity to get help from the scholars, knowledgeable people, and specialists to solve problems like these ones.

In this section, the researchers will cover and display the several parties who can provide assistance to the institution, in order to get the suitable technology for it, and in accordance with the acceptable terms and specifications, along with exposing the project manager's role in overcoming obstacles associated with the process of purchasing and operating the technology:

6.1. The role of project manager in overcoming obstacles associated with the process of purchasing and operating the technology:

The problem that nations suffer from, is no longer represented in the possession of technology, but becomes in the way that used to purchase and operate the technology itself, because technology doesn't mean only the non- 
developed countries imports of factories, machines, and developed production methods from the developed countries, but also means the process of adapting these factories, technological equipments, and sophisticated production methods, with the local conditions and circumstances of the territories and environments that invests in it, which at the end puts a great burden on the project management responsible for decision of purchasing and operating the technology, since those decisions considers one of the strategic decisions that have impact on the economic and social situation of each project and society.

Therefore, the decision-making process is the core and essence of management, and Simon wasn't unreasonable when he used the word management to mean decision-making and the word decision-making to mean management, and that means the decision makers associated with purchasing and operating the technology have to recognize there is a clear difference between the methods and techniques of modern technology and local conditions of the countries that technology transfer to, and this difference leads to unsuccessful adaptation between the foreign technology and modern systems and the existing circumstances and conditions in the countries that technology transfer to, which causes in most cases an inability to continue and grow, or even fail sometimes. This puts responsibility on the projects management department in Jordan, the burden to first change and modify the behavioral patterns and current standards, and then train technical staffs and develop the scientific and practical systems related to purchasing and operating the technology, from the appropriate sources, at the specifications that agrees with the project needs and requirements, and at the lowest possible cost. This illustrates that purchasing and operating the technology won't be useful, if there wasn't a management at high level of efficiency which is capable of dealing with all factors associated with purchasing and operating the technology.

The public sector in most non-developed countries, including Jordan plays a major role in the process of purchasing and operating technology, therefore the decisions that Jordan takes, in this regard have either positive or negative impacts on the purchasing and operating process, depending on the quality of decisions taken and the adaptation level of clear policy, therefore success of the purchasing process depends directly on the capability and efficiency of the decision makers associated with this sector, and their level of understanding and knowledge of the national development plans and their technological needs, and since most workers in this sector lacks the knowledge related to purchasing and operating the technology, and the potentials and possibilities that allows them to use it, the awareness and readiness of those workers, becomes very important matter and crucial, and this explains the relationship between management and technology.

\subsection{The role of international organizations in the process of purchasing and operating technology:}

The United Nations and its affiliated organizations helps with transferring technology to the non-developed countries, including Jordan, through the assistance they provide for this area, through its research centers, the conferences and seminars that have been hold in this regard, or train the non-developed countries staffs by the international organization, and provide the necessary information for them, about the technology they need, and implement the programs to increase efficiency and performance of specific services.

"Perhaps the conference held in Vienna, August,1979, and attended by 141 countries, shows the international organization level of interest in the technology topic, and discussions were held about the possibility of nondeveloped countries to benefit from the technology and strive to develop the scientific and technological potentials and capabilities of those countries, to overcome its problems, and perhaps the most important declaration; in this regard is, The claim to support the non-developed countries in their efforts to obtain the technology and provide the financial resources for this purpose"( Annual Report (1995)) . There are also international organizations that not part of the United Nations, but rather regional organizations which perform similar services to the one done by the international organizations.

6.3. The role of local advisory and counseling expertise offices in the process of purchasing and operating the technology:

The advisory and consult companies performs several tasks, including assist companies in the process of purchasing and operating the technology, these companies or consulting firms perform this task in behalf of these companies due to their inability to practice this task. For that purpose, countries try to create specialized system to play the role of expertise houses, and follow on the ministries, because the government sector is the largest importer of technology, and "the technology owned by the expertise house considers its balance of employees accumulated knowledge, and benefit from it to provide consultations, the important of these institutions comes from its connections and relations with the technology producers, purchasers and financial institutions in the nondeveloped countries, and the international organizations, these institutions have the ability to link the political, economical, and technological aspects, as a result of its communication and relationships"( Annual Report (1996)).

7. For Jordan, the country choose to assign this task to the Jordanian Royal Society, which was established in 1970 , to be the first scientific center that cares about the scientific and technological development, and works to deliver its services and advices in the field of scientific and technological research to the public and 
private sector. It also signed a lot of agreements with the research and technological institutions on the Arab world and international level, including the Academy of Scientific Research \& Technology in Egypt, where "academy contains more than 130 of masters and $\mathrm{PhD}$ holders, in addition to the staff employees, where the academy have more than 35 dependent laboratories locally and internationally in the areas of industry and technology" (Supplement to the Study (1998)).

"In 1987, the Jordanian leadership felt, with its believes in the importance of scientific and technological research, to create the higher center for science and technology, while the Jordanian Royal Society will be one of its institutions, where the goal of establishing this council is to build national scientific and technological foundation that contributes to achieve the development objectives, and support creativity and leadership, which contribute to the transformation of scientific and technological ideas and thoughts into commercial products and businesses, and also holds agreements and scientific and technological cooperation with the local and regional sides, and among its objectives build the national scientific and technological capabilities, and works to develop it and disseminate it in the various aspects of life, in addition to the focus on advanced technology applications in the various fields, and provide the technical potentials for the scientific research institutions "1.

There are also other research centers that subject to the private sector, and also scientific and technological centers within the universities that offers the advisory services in the field of purchasing and operating technology, and works as partner with the outside consultant and advisors, "where studies have shown that the proportion of units that perform by the research and development activity is (60\%) from the Sample size of 524 institutions, the number of workers in these research units, 24504 workers, 9415 scientists, scholars, and engineers, 3466 technical, 5546 technician, and 6073 management"'2.

The above research centers is concerned with the approval to allows the appropriate technology into Jordan environment, and also works to develop it and disseminate it in the future.

\section{The applied (field) study:}

\subsection{Preliminary:}

After reviewing the previous items related to the impact and reflections of management environment in purchasing and operating the technology, this item is intended to identify the measurement of management environmental factors impact on the decision of purchasing and operating technology, through identifying the concerned people point of view in the Jordanian institutions, as the responsible party for purchasing and operating the technology.

\subsection{Study methodology:}

This study focused on the concerned people of purchasing and operating the technology in Jordan, the working corporate managers and decision makers in both sectors, public and private, who were covered by the questionnaire, and the concerned category was also assimilated in providing its advisory services in this field, such as workers in the scientific and academic research centers.

\subsection{Questionnaire list design:}

The researchers were dedicated to the questionnaire list to include a set of questions, which covers the required inquiries and questions of management environment efficiency and its reflections on the purchasing decision maker, and these questions were designed through four major angles.

\subsection{Measurement consistency:}

The consistency checks for the study tool was done by (Test-Retest) method, and calculation of the internal consistency using (Cronbach Alpha) equation, by distributing the study tool on a explorative sample composed of (30) employees; males and females from the experts and specialize professors, to identify their comments and notes from outside the study sample where the study tool was implemented. Table (1) shows the reliability and consistency coefficients, Pearson correlation coefficients for the study dimensions, and the measurement as a whole. 
Table 1 . The results of internal consistency coefficients between study areas

\begin{tabular}{|c|c|c|}
\hline Dimension & Cronbach alpha value & $\begin{array}{c}\text { Pearson correlation } \\
\text { coefficient value }\end{array}$ \\
\hline $\begin{array}{c}\text { The importance of technology purchasing and } \\
\text { acquisition for Jordan }\end{array}$ & 0.87 & $0.775^{*}$ \\
\hline $\begin{array}{c}\text { Illustrate the impact of internal and external managerial } \\
\text { environment on the decision of purchasing and } \\
\text { operating the technology }\end{array}$ & 0.849 & $0.741^{*}$ \\
\hline $\begin{array}{c}\text { Obstacles of purchasing and operating the technology. } \\
\text { its special services in purchasing and operation } \\
\text { technology. }\end{array}$ & 0.930 & $0.981^{*}$ \\
\hline $\begin{array}{c}\text { Readiness of research and advisory centers to provide } \\
\text { Overall measurement }\end{array}$ & 0.956 & $0.922^{*}$ \\
\hline
\end{tabular}

* Statistically significant at a level $(\alpha \geq 0.05)$

It noticed from table (1), that values of consistency coefficients, Pearson correlation coefficients for the study dimensions, and the measurement as a whole are medium and high values, and therefore it's sufficient to conduct the study. The questionnaire was also distributed to group of academics and researchers, who contributes effectively to the mentoring and guiding process of purchasing the technology that aligns with Jordan needs.

\subsection{Study populations:}

The study population considers a practical study field; in this research, they are the concerned stakeholders, and the decision makers of purchasing and operating technology in the Jordanian institutions, in both sectors, public and private.

\subsection{Study sample:}

In regard to the study sample, the researchers felt this sample must represent the population or society, truly and faithfully, therefore the researchers were dedicated to distribute the questionnaire on most of the public institutions, which operate under the government, as well as the private institutions, and these which had a head start, since the 50s of the 19th century in purchasing and operating the technology, which always work on the replacement and renewal of its equipments, such as potash, phosphate, cement, chemical fertilizers, and many other companies.

Researchers finds this sample to represent $(20 \%)$ from the study population, which needs to determine its point of view, in regard to the impact of management environment and its reflections on the decision of purchasing and operating the technology in the Jordanian institutions, where the study sample consisted of (165) employees; males and females, who were chosen at random from the study population. Table (2) shows the distribution of sample members, according to personal data: 
Table 2. Distribution of study sample members according to personal data

\begin{tabular}{|c|c|c|c|}
\hline Variables & Level & Frequency & $\%$ \\
\hline \multirow{2}{*}{ Sex } & Male & 135 & 81.8 \\
\hline & Female & 30 & 18.2 \\
\hline \multirow{4}{*}{ Age } & $30 \mathrm{yrs}$ or less & 6 & 3.6 \\
\hline & Between (31-40) yrs & 46 & 27.9 \\
\hline & Between (41-50) yrs & 67 & 40.6 \\
\hline & 51 yrs or more & 46 & 27.9 \\
\hline \multirow{4}{*}{ Qualification } & Diploma or less & 16 & 9.7 \\
\hline & Bachelor degree & 100 & 60.6 \\
\hline & Master degree & 34 & 20.6 \\
\hline & $\mathrm{PhDs}$ & 15 & 9.1 \\
\hline \multirow{4}{*}{ Job level } & Unit Head & 15 & 9.1 \\
\hline & Section Head & 57 & 34.5 \\
\hline & Department Manager & 84 & 50.9 \\
\hline & General Manager & 9 & 5.5 \\
\hline \multirow{3}{*}{ Years of experience } & $3-5$ yrs & 10 & 6.1 \\
\hline & $6-10$ yrs & 21 & 12.7 \\
\hline & $11 \mathrm{yrs}$ and more & 134 & 81.2 \\
\hline \multicolumn{2}{|c|}{ Total } & 165 & 100.0 \\
\hline
\end{tabular}

It shows from table (2) the following:

1. The number of males in the study sample amounted to (135), at (81.8\%), while the number of females (30), at (18.2\%).

2. The highest distribution percentage of the sample members, according to the age variable amounted to $(40.6 \%)$, for the age group (41-50 yrs), while the lowest came to $(3.6 \%)$, for the age group (30 yrs or less).

3. The highest distribution percentage of the sample members, according to the qualification variable amounted to $(60.6 \%)$, for the bachelor degree, while the lowest came to $(9.1 \%)$, for the $\mathrm{PhD}$ degree.

4. The highest distribution percentage of the sample members, according to the job level variable amounted to $(50.9 \%)$, for the department head level, while the lowest came to $(5.5 \%)$, for the general manager level.

5. The highest distribution percentage of the sample members, according to the years of experience variable amounted to $(81.2 \%)$, for the years of experience (11 yrs or more), while the lowest came to $(6.1 \%)$, for the years of experience (3-5 yrs).

In order to obtain an analysis of the results of the questionnaire, computer has been used, where the statistical package for the social sciences (SPSS) was used, which considers one of the most appropriate methods for such purpose.

\subsection{Results display:}

This section includes a presentation of study results, which aims to identify the management environment and its reflection on the efficiency of purchasing and operating the technology, the following is a presentation for the results of the research, in accordance with the study questions:

\subsubsection{First question: what are the difficulties that interrupt the decision of purchasing and operating} the technology in the non-developed countries, especially Jordan?

To answer this question, the arithmetic means and standard deviations have been calculated for the answers of sample members on the difficulties dimension articles, which interrupt the process of purchasing and operating the technology, and the dimension as a whole, and also executes the (One sample T-test) on the difficulties 
dimension as a whole, and tables $(3,4)$ illustrates that:

Table 3. Arithmetic means and standard deviations for the estimates study sample members on the difficulties and obstacles dimension as a whole in descending order

\begin{tabular}{|c|c|c|c|c|}
\hline \multirow{2}{*}{ Number } & Articles & Mean * & $\begin{array}{c}\text { STDE } \\
\text { V }\end{array}$ & $\begin{array}{c}\text { Acceptance } \\
\text { degree }\end{array}$ \\
\hline 6 & Private sector more flexible about making purchasing decision & 4.45 & 0.852 & High \\
\hline 2 & Purchasing decision needs negotiation special skills. & 4.39 & 0.660 & High \\
\hline 4 & Lack of Jordanian capital investment in the advanced & 3.94 & 1.004 & High \\
\hline 3 & Jochnology project. & 3.87 & 0.957 & High \\
\hline 1 & Narrowness and limitation of Jordanian market, limit the \\
decision of purchasing the advance technology. & 3.49 & 1.028 & Medium \\
\hline 5 & Jordanian institutions management are eligible to take the \\
decision of purchasing the technology. & 3.28 & 0.960 & Medium \\
\hline 7 & $\begin{array}{c}\text { Difficulties dimension that faces purchasing and operating the } \\
\text { technology as a whole }\end{array}$ & 3.91 & 0.472 & High \\
\hline
\end{tabular}

* Maximum degree from (5)

It shows through table(3) that arithmetic means for difficulties dimension articles, which interrupt the process of purchasing and operating the technology ranging from (3.28-4.45) at medium and high degrees of acceptance, where the highest was for articles (6) "Private sector is more flexible in making the purchasing decisions, with a standard deviation of (0.852), followed by the arithmetic mean (4.39) for articles (2) "Purchasing decision need special skills in negotiation", with a standard deviation of (0.660), while the lowest was for articles (5) "Management of Jordanian institutions qualified to take the decision of purchasing the technology. The arithmetic mean for the dimension, as a whole amounted to (3.91), with high approval degree.

Table 4. Results of implementing (one sample t-test) on the dimension of difficulties and obstacles that faces purchasing and operating the technology as a whole

\begin{tabular}{|c|c|c|c|c|}
\hline Dimension & Mean & T-value & sensitivity & Siq \\
\hline Obstacles that faces purchasing and operating the technology. & 4.063 & 24.601 & 164 & $\begin{array}{c}0.000 \\
*\end{array}$ \\
\hline
\end{tabular}

* Statistically significant at a level $(\alpha \geq 0.05)$

It shows from table (4), that T-value for the difficulties dimension, which interrupt the process of purchasing and operating the technology amounted to (24.601), which is statistically significant value at level $(\geq \alpha 0.05)$, indicating the existence of difficulties that interrupt the decision of purchasing and operating the technology in the non-developed countries, especially Jordan.

\subsubsection{Second question: what is the importance of technology acquisition on the decision of purchasing it and operating it in Jordan?}

To answer this question, the arithmetic means and standard deviations have been calculated for the answers of sample members on the technology acquisition dimension articles, which interrupt the decision of purchasing and operating the technology, and the dimension as a whole, and also executes the (One sample T-test) on the technology acquisition dimension as a whole, and tables $(5,6)$ illustrates that: 
Table 5. Arithmetic means and standard deviations for the estimations of study sample members on the purchasing and acquisition dimension as a whole in descending order

\begin{tabular}{|c|c|c|c|c|}
\hline \multirow{2}{*}{ Number } & Articles & Mean * & $\begin{array}{c}\text { STDE } \\
\text { V }\end{array}$ & $\begin{array}{c}\text { Acceptance } \\
\text { degree }\end{array}$ \\
\hline 1 & Technology use leads to additional economical development & 4.60 & 0.795 & High \\
\hline 6 & Employment-intensive technology is appropriate for Jordan & 4.38 & 0.568 & High \\
\hline 2 & Technology leads to the luxury of individual and society & 4.32 & 0.848 & High \\
\hline 3 & Provide an Arabic and foreign development investments & 4.31 & 0.921 & High \\
\hline 8 & Use of technology requires changing the behavioral pattern & 4.08 & 0.776 & High \\
\hline 7 & Jordan industries need developed and advanced technology & 3.85 & 0.908 & High \\
\hline 5 & Jordanian society accepts the rapid changes in technology & 3.70 & 1.111 & High \\
\hline 4 & Absorb part of the unemployment experienced by society & 3.25 & 1.057 & Medium \\
\hline \multicolumn{2}{|c|}{ Purchasing and acquisition technology dimension as a whole } & 4.063 & 0.454 & High \\
\hline
\end{tabular}

* Maximum degree from (5)

It shows through table (5), that arithmetic means for technology acquisition dimension articles, which interrupt the process of purchasing and operating the technology ranging from (3.25-4.60) at medium and high degrees of acceptance, where the highest was for articles (1) "The use of technology leads to more economical development", with a standard deviation of (0.795), followed by the arithmetic mean (4.38) for articles (6) "Intensive employment technology are suitable for Jordan", with a standard deviation of (0.568), while the lowest was for articles (4) "Absorb part of unemployment experienced by society". The arithmetic mean for the dimension, as a whole amounted to (4.063), with high approval degree.

Table 6. The results of implementing (one sample t-test) on technology acquisition dimension, as a whole

\begin{tabular}{|c|c|c|c|c|}
\hline Dimension & Mean & T-value & DF & Sig \\
\hline $\begin{array}{l}\text { Technology } \\
\text { acquisition }\end{array}$ & 4.063 & 30.074 & 164 & $0.000 *$ \\
\hline
\end{tabular}

* Statistically significant at level $(\alpha=0.05)$

It shows from the previous table (6), that T-value for the technology acquisition dimension, which interrupt the process of purchasing and operating the technology amounted to (30.074), which is statistically significant value at level ( $\geq \alpha 0.05)$, indicating the existence of importance for technology acquisition in the decision of purchasing and operating the technology in the non-developed countries, especially Jordan.

\subsubsection{Third question: what are the restrictions and limitations of internal and external managerial environment?}

To answer this question, the arithmetic means and standard deviations have been calculated for the answers of sample members on the management environment restrictions and limitations dimension articles, which interrupt the decision of purchasing and operating the technology, and the dimension as a whole, and also executes the (One sample T-test) on the management environment restrictions and limitations dimension as a whole, and tables $(7,8)$ illustrates that: 
Table (7) arithmetic means and standard deviations for the estimations of study sample members on the limitations and restrictions of managerial environment dimension as a whole in descending order

\begin{tabular}{|c|c|c|c|c|}
\hline Number & Articles & Mean * & STDEV & $\begin{array}{l}\text { Acceptance } \\
\text { degree }\end{array}$ \\
\hline 4 & $\begin{array}{l}\text { Purchasing technology decision at public } \\
\text { sector institutions is centrally taking }\end{array}$ & 4.33 & 0.898 & High \\
\hline 2 & $\begin{array}{l}\text { Imbalance between the education outputs } \\
\text { and the technology operating requirements }\end{array}$ & 4.08 & 0.858 & High \\
\hline 1 & $\begin{array}{l}\text { The inefficiency and ineffectually of } \\
\text { changing government legislation leads to } \\
\text { refusal from purchasing the advanced } \\
\text { technology }\end{array}$ & 4.03 & 0.851 & High \\
\hline 3 & $\begin{array}{l}\text { The scarcity of wealth elements in society } \\
\text { which needs advanced and developed } \\
\text { technology }\end{array}$ & 3.40 & 1.092 & Medium \\
\hline 5 & $\begin{array}{l}\text { Limitations of managerial environment } \\
\text { dimension as a whole }\end{array}$ & 3.96 & 0.590 & High \\
\hline
\end{tabular}

* Maximum degree from (5)

It shows through table (7), that arithmetic means for management environment restrictions and limitations dimension articles, which interrupt the process of purchasing and operating the technology ranging from (3.404.33) at medium and high degrees of acceptance, where the highest was for articles (4) "The decision of purchasing technology in the public sector will be taken in a centralized way", with a standard deviation of (0.898), followed by the arithmetic mean (4.08) for articles (2) "Imbalance between the educational outputs and requirements for operating the technology", with a standard deviation of (0.858), while the lowest was for articles (3) "The scarcity of wealth elements in the societies that need sophisticated technology". The arithmetic mean for the dimension, as a whole amounted to (3.960), with high approval degree.

Table 8 . The results of implementing (one sample t-test) on limitations of managerial environment dimension, as a whole

\begin{tabular}{|c|c|c|c|c|}
\hline Dimension & Mean & T-value & DF & Sig \\
\hline $\begin{array}{l}\text { Technology } \\
\text { acquisition }\end{array}$ & 3.96 & 20.885 & 164 & $0.000 *$ \\
\hline
\end{tabular}

* Statistically significant at level $(\alpha=0.05)$

It shows from the previous table (8), that $\mathrm{T}$-value for the management environment restrictions and limitations dimension, which interrupt the process of purchasing and operating the technology amounted to (20.885), which is statistically significant value at level $(\geq \alpha 0.05)$, indicating the existence of internal and external management environment restrictions and limitations in the decision of purchasing and operating the technology in the nondeveloped countries, especially Jordan.

\subsubsection{Fourth question: what is the role of research and advisory centers in Jordan by contributing to} rationalize decision of purchasing and operating the technology?

To answer this question, the arithmetic means and standard deviations have been calculated for the answers of sample members on the research and advisory centers readiness dimension, which interrupt the decision of purchasing and operating the technology, and the dimension as a whole, and also executes the (One sample T-test) on the research and advisory centers readiness dimension as a whole, and tables $(9,10)$ illustrates that: 
Table 9. Arithmetic means and standard deviations for the estimations of study sample members on the readiness of research and advisory centers dimension as a whole in descending order

\begin{tabular}{|c|c|c|c|c|}
\hline Number & Articles & Mean * & STDEV & Acceptance degree \\
\hline 4 & $\begin{array}{l}\text { Preference of purchasing already made } \\
\text { technology (turnkey) }\end{array}$ & 3.86 & 1.059 & High \\
\hline 2 & $\begin{array}{l}\text { Scientific research centers and universities are } \\
\text { eligible to provide advice before purchasing } \\
\text { the technology }\end{array}$ & 3.82 & 0.788 & High \\
\hline 1 & $\begin{array}{l}\text { Public sector institutions rely on third / } \\
\text { external parties before purchasing the } \\
\text { technology }\end{array}$ & 3.74 & 0.869 & High \\
\hline 5 & $\begin{array}{l}\text { Preference of joint property of purchasing } \\
\text { technology }\end{array}$ & 3.58 & 0.964 & Medium \\
\hline 6 & $\begin{array}{l}\text { Preference of purchasing and using patented } \\
\text { technology project }\end{array}$ & 3.49 & 1.146 & Medium \\
\hline 7 & $\begin{array}{l}\text { Preference of purchasing part of technological } \\
\text { project }\end{array}$ & 3.31 & 0.888 & Medium \\
\hline 3 & $\begin{array}{l}\text { Public sector institutions consult specialized } \\
\text { local bodies before purchasing the technology }\end{array}$ & 3.29 & 0.975 & Medium \\
\hline 8 & $\begin{array}{l}\text { Readiness of research and advisory centers } \\
\text { dimension as a whole }\end{array}$ & 3.584 & 0.520 & Medium \\
\hline
\end{tabular}

* Maximum degree from (5)

It shows through table (9), that arithmetic means for research and advisory centers readiness dimension articles, which interrupt the process of purchasing and operating the technology ranging from (3.29-3.86) at medium and high degrees of acceptance, where the highest was for articles (4) "The preference of purchasing already made technology (turnkey)", with a standard deviation of (1.059), followed by the arithmetic mean (3.82) for articles (2) "Scientific research centers and universities are eligible to provide advice before purchasing the technology", with a standard deviation of (0.788), while the lowest was for articles (3) "Public sector institutions consult specialized local bodies before purchasing the technology". The arithmetic mean for the dimension, as a whole amounted to (3.584), with medium approval degree.

Table 10. The results of implementing (one sample t-test) on readiness of research and advisory centers dimension as a whole

\begin{tabular}{|c|c|c|c|c|}
\hline Dimension & Mean & T-value & DF & Sig \\
\hline $\begin{array}{c}\text { Readiness of } \\
\text { research and } \\
\text { advisory centers }\end{array}$ & 3.584 & 14.421 & 164 & $0.000 *$ \\
\hline
\end{tabular}

* Statistically significant at level $(\alpha=0.05)$

It shows from the previous table (10), that T-value for the research and advisory centers readiness dimension, which interrupt the process of purchasing and operating the technology amounted to (14.421), which is statistically significant value at level $(\geq \alpha 0.05)$, indicating the existence of a role for the research and advisory centers in Jordan by contributing to rationalize the decision of purchasing and operating the technology in Jordan.

\section{Conclusion}

According to what has been reviewed in the theoretical part of this study, it is clear how important it is to address the issue of the administrative environment and its impact on the efficiency, purchase and operation of technology in developing countries in general and in Jordan in particular. These countries need to use technology 
with particular specifications that depends on their communities, as well as improving the productivity of individuals and reduces unemployment rate of these countries.

The results of the study were fully consistent with its theoretical part. It included the survey of 165 directors of different companies as well as who's interested in purchasing technology and its' operating in the region of Jordan. The sample represented $20 \%$ of population study, where the answers of questionnaire concerned on proving the validity of the study hypotheses included in the methodological framework of the study. Which were quite consistent with the results.

As for the first hypothesis, the arithmetic average was high, reaching 3.9 degrees of 5 degrees, which is the core. In this context, the private sector has more flexibility of making purchasing decisions and obtained 4.45 out of 5 points. This also follows the rhythm of third hypothesis as shown in Table 2.

The second hypothesis approved since the purchasing decision in the governmental and public sector is centralized and obtained 4.33 out of 5 grades, which is also high, as shown in Table 6 , these values reduces the ability of purchasing technology and its operating in these sectors in contrast to the private sectors.

The fourth hypothesis related to the failure of the scientific research centers to provide advice in the field of technology purchasing. The responses obtained an average of 3.87 out of 5 grades as shown in Table 8 . While the responses to the public sector's reliance on external advice was obtained, 3.74 degrees out of 5 degrees, which is also high as shown in Table 8.

Accordingly, it is possible to conclude that what was presented in the theoretical part of the study was fully consistent with the responses in the literature and the hypotheses of the study.

\section{References}

Anissimov, M., \& Bronwyn H. (2018) “What Is Technology?” [Online] WiseGEEK, Conjecture Corporation, Available: www.wisegeek.org/what-is-technology.htm\#. (25 Jan. 2019)

Ballou, R. H. (2004). Business Logistics/supply Chain Management: Planning, Organizing, and Controlling the Supply Chain. (5th ed.). Upper Saddle River, N.J.: Pearson/Prentice Hall.

Ismail, M. (1976). Problems of technology transfer from developed countries to developing countries, development and international economic relations. Annual Scientific Conference of Egyptian Economists, Egyptian Association for Political Economy, Statistics and Legislation, Cairo, pp. 283. - In Arabic

Mansfield, E (1968). The Economics of Technological Change. The Economics of Technological Change, Norton, pp. 444-449.

Abu-Ismail, F (1983). The Environment and its Impact on the Acquisition of Kuwaiti Companies for Technology, Journal of Gulf Studies and Al-Jazeera, Vol. 8, Kuwait, Kuwait University, pp. 43

Farmer, R. N., \& Barry M. R. (1966). Comparative Management and Economic Progress. The International Executive, vol. 8, no. 1, pp. 345-349., doi:10.1002/tie.5060080110.

Ezzedine, S. (1981). Technological Transformation, Arab Unity Studies, July 1981, pp. 29-45

Fawzi, A.-A. (1983), Management of Technology in Developing Countries, Library of Administration, First Issue, Riyadh: Institute of Public Administration, October 1983, pp. 114-115.

Annual Report (1995), Journal of the Royal Scientific, Issue 60, Amman, April 1995, pp. 18-19

Annual Report (1996), Journal of the Royal Scientific, Issue 61, Amman, April 1996, pp. 2-4

Supplement to the Study (1998), The Supreme Council for Science and Technology, National Scientific and Technological Needs and Potential, Phase II, Amman, 1998 pp. 2-3 